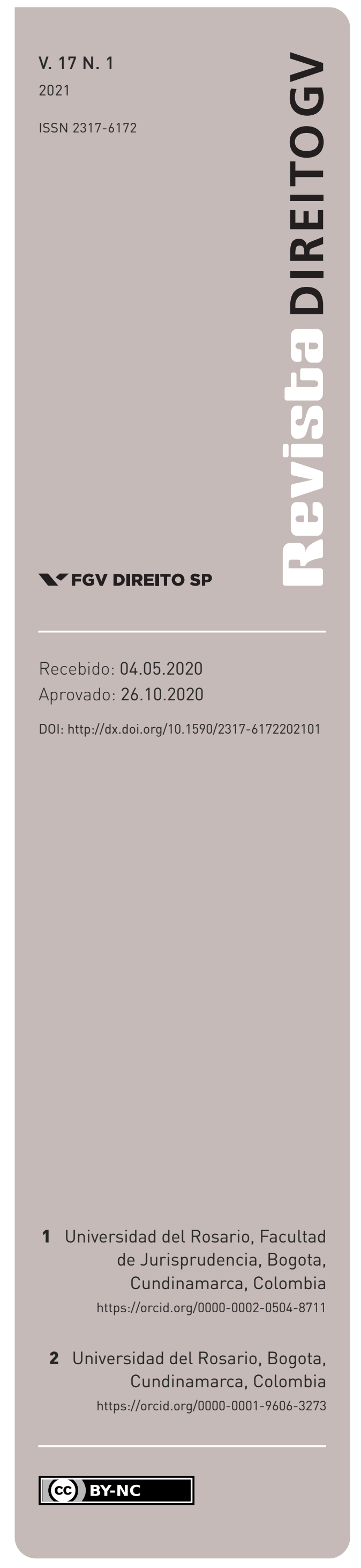

\title{
Un estudio sobre la posibilidad de aplicar la inteligencia artificial en las decisiones judiciales
}

\author{
A STUDY ON THE POSSIBILITY OF APPLYING ARTIFICIAL INTELLIGENCE IN JUDICIAL DECISIONS
}

UM ESTUDO SOBRE A POSSIBILIDADE DEAPLICAÇÃO DA INTELIGÊNCIA ARTIFICIAL EM

DECISÕES JUDICIAIS

Erick Rincón Cárdenas ${ }^{1}$ y Valeria Martinez Molano²

\section{Resumen}

La inteligencia artificial es una herramienta que cada vez se encuentra más presente en el desarrollo de las actividades cotidianas realizadas por los seres humanos, $y$, en esta medida, se busca aplicarla en diferentes sectores, como lo es el campo del Derecho, principalmente en lo relacionado con las decisiones judiciales. Este artículo pretende resolver diferentes interrogantes que existen en relación a la aplicación de inteligencia artificial a decisiones judiciales, analizando si la misma genera utilidad, si es factible su implementación y las consecuencias que trae consigo que un sistema jurídico experto participe en la toma de decisiones jurídicas.

Como resultado de esta investigación académica y teórica, se determina que la participación de un sistema experto jurídico en la toma de decisiones judiciales tiene como principal implicación el aumento de la seguridad jurídica en el sistema judicial, como consecuencia de un aumento de confianza en la misma. Dicho aumento de confianza, acompañado de la mayor celeridad de la administración de justicia, puede justificar los costos que tiene su aplicación. No obstante las ventajas, no se puede desconocer que la responsabilidad de estas decisiones recaerá siempre en el ser humano, para el caso concreto en el juez.

\section{Palabras clave}

Inteligencia artificial; sistema de expertos jurídicos; seguridad jurídica; descongestión; responsabilidad; administración de justicia.

\begin{abstract}
Artificial intelligence is a tool that is increasingly present in the development of daily activities carried out by human beings, and, to this extent, it is applied in different sectors such as the field of Law, mainly in relation to judicial decisions. This article aims to resolve different questions that exist in relation to the application of artificial intelligence to judicial decisions, analyzing whether it is useful, whether its implementation is feasible and what are the consequences when an expert legal system participates in legal decision-making.

As a result of this academic and theoretical research, it is determined that the participation of an expert legal system in judicial decision-making has the main implication of increasing legal certainty in the judicial system, as a consequence of an increase in trust in it. Such an increase in confidence, accompanied by the greater speed of the administration of justice, can justify the costs of its application. Despite the advantages, it cannot be ignored that the responsibility for these decisions will always fall on the human being, for the specific case, on the judge.
\end{abstract}

\section{Keywords}

Artificial intelligence; legal expert system; legal certainty; decongestion; liability; justice administration. 


\begin{abstract}
Resumo
A inteligência artificial é uma ferramenta que está cada vez mais presente no desenvolvimento das atividades cotidianas realizadas por seres humanos, e, nesse sentido, é aplicada em diferentes setores, como o campo do Direito, principalmente em relação a decisões judiciais. Este artigo tem como objetivo responder diferentes questões que existem em relação à aplicação da inteligência artificial nas decisões judiciais, analisando se ela é útil, se sua implementação é viável e quais são as consequências quando um sistema jurídico especialista participa da tomada de decisão legal.

Como resultado desta pesquisa acadêmica e teórica, determina-se que a participação de um sistema jurídico especializado na tomada de decisões judiciais tem como principal implicação o aumento da segurança jurídica no sistema judicial, como consequência do aumento da confiança nele. Tal aumento de confiança, acompanhado pela maior velocidade da administração da justiça, pode justificar os custos de sua aplicação. Apesar das vantagens, não se pode ignorar que a responsabilidade por essas decisões sempre recairá sobre o ser humano, no caso específico, sobre o juiz.
\end{abstract}

\title{
Palavras-chave
}

Inteligência artificial; sistema de especialistas jurídicos; segurança jurídica; descongestionamento; responsabilidade e administração de justiça.

\section{Introducción}

La expresión inteligencia artificial (IA) fue acuñada por primera vez en 1956, por expertos interesados en construir una máquina que fuera tan inteligente como el humano, presentando así por primera vez en la Universidad de Dartmouth una computadora inteligente capaz de realizar diversas funciones (AMÉRICA RETAIL, 2019). Empero, sus estudios se remontan a décadas atrás, razón por la cual sus contenidos, alcances y conceptos han sufrido modificaciones en el tiempo, manteniendo la utilización de "sistemas de expertos" que buscan solucionar problemas y fomentar la toma de decisiones más allá de las posibilidades humanas (GARCÍA, 2018).

Como lo define Bruno López (2017), la inteligencia artificial es una rama de las ciencias computacionales que se encarga de estudiar modelos de cómputo capaces de realizar actividades propias de los seres humanos con base en el razonamiento y la conducta.

En otras palabras, la inteligencia artificial es la posibilidad de que sistemas y máquinas lleguen a realizar acciones complejas que tradicionalmente se consideraban propias de los seres humanos, de manera incluso más eficiente y rápida.

Se tiene previsto que con el tiempo y el desarrollo tecnológico la inteligencia artificial genere cambios en la sociedad, en donde sistemas inteligentes desarrollen toda clase de funciones. Por ende, teniendo en cuenta el panorama actual de la inteligencia artificial, mucho 
se ha cuestionado sobre su posible aplicación en el Derecho, principalmente en lo referente a la función jurisdiccional.

El conjunto de la inteligencia artificial y el Derecho pretenden realizar estructuraciones lógicas, ordenadas y analíticas, así como la interpretación de la dogmática jurídica a través de las Tecnologías de la Información y Comunicaciones (en adelante TIC) (BATISTA \& NAVARRETE, 2019). Por tanto, como lo han señalado algunos doctrinantes, la inteligencia artificial aplicada al Derecho se ve reflejada en cuatro áreas a saber (NAVA, 2019):

1. modelos para la argumentación y toma de decisiones;

2. clasificación y extracción de textos legales;

3. extracción de información de textos legales;

4. creación y planificación de un sistema legislativo.

Para analizar la inteligencia artificial respecto a las decisiones judiciales, se debe tener en cuenta que al momento de tomar decisiones los jueces realizan análisis y procesos mentales en donde tienen en cuenta elementos subjetivos y objetivos, así, se basan en su propio criterio en conjunto con el análisis de la ley, los hechos, las pruebas, los criterios jurisprudenciales, doctrinantes, entre otros.

Teniendo en cuenta las herramientas de los jueces al momento de tomar decisiones judiciales, y en relación con el nivel de desarrollo que tiene actualmente la inteligencia artificial, se ha permitido que abogados, en sintonía con científicos informáticos, desarrollen proyectos que habiliten realizar algunas de las tareas y procesamientos analíticos que tienen los jueces al momento de tomar una decisión.

Un ejemplo del desarrollo de la IA en las decisiones judiciales se encuentra en el proyecto Prometea. En el año 2017 en Argentina se desarrolló el primer sistema de inteligencia artificial predictivo que trabaja con un asistente de voz, el cual permite realizar un dictamen jurídico de manera íntegra.

En Colombia para el año 2019 estaba en prueba el sistema Prometea, que tenía por objeto para el caso colombiano contribuir al proceso de revisión de fallos de tutela. Su principal función es la selección y preselección de las tutelas que serán conocidas por la Corte Constitucional, mediante criterios generados por el propio juez. Adicionalmente, se espera que se realicen análisis estadísticos que permitan al operador judicial la toma de decisiones jurídicas y de políticas públicas. Prometea es un prototipo, sin ser vinculante para la Corte Constitucional, por ende, será esta entidad quien determinará su implementación (SIERRA, 2019).

Con lo hasta acá expuesto se puede evidenciar la importancia e influencia que ha tenido la inteligencia artificial en el campo de las decisiones judiciales; sin embargo, y pese al gran 
avance y utilidad en la materia, todavía se presentan problemas jurídicos que deben ser resueltos y que en el presente artículo se pretenden desarrollar, para realizar así un aporte significativo al campo de la inteligencia artificial en el Derecho. De esta manera, se pretenden resolver los siguientes interrogantes:

: ¿Qué implicaciones tendría en la seguridad jurídica de un sistema judicial, la adaptación de un sistema de expertos jurídicos para tomar decisiones y emitir providencias?

: ¿Los costos en que se incurrirían para implementar sistemas expertos jurídicos serían justificables con la subsiguiente descongestión del sistema judicial?

: ¿Cuál sería el nivel de responsabilidad del juez y del diseñador del sistema de expertos jurídicos que toma decisiones judiciales ante un funcionamiento incorrecto del mismo?

\section{El Desarrollo de la inteligencia artificial en el Derecho}

Como se ha manifestado, las tecnologías han permeado la totalidad de las áreas de la cotidianidad, entre ellas el Derecho, generando que autores como los hermanos Susskind (2016) se cuestionen sobre los roles tradicionales y los desafíos que las aplicaciones de inteligencia artificial imponen en la profesión.

Una de las primeras aplicaciones tecnológicas, implementada mediante la máquina de cálculo automático al ambiente legal, se dio en la Cámara de Representantes del Estado de Ohio en 1938. No obstante, fue hasta el año 1949 cuando el jurista norteamericano Lee Loevinger publica su texto "Jurimetrics. The next step forward", en donde se crea el concepto de Jurimetría, como referencia a la aplicación de la automatización para contribuir a la racionalización del Derecho, planteando la posibilidad de prever las decisiones jurídicas sobre los cálculos de base empírica (REYES, 2019).

Teniendo en cuenta tales antecedentes, con base en lo dicho por Allen (1962), en el año 1961 un informe del Jurimetrics Committee of the Association of American Law School, señala que en el campo de la jurimetría tenían especial interés en asuntos como el análisis cuantitativo de los aspectos de las decisiones jurídicas (REYES, 2019). Por tanto, se puede evidenciar que ya para la fecha se planteaba la posibilidad de aplicar las tecnologías a las decisiones judiciales.

En la actualidad, tal como lo señala Fernando Linares (2018) lo que se entiende bajo la denominación de inteligencia artificial hace referencia a una gran cantidad de técnicas avanzadas para el procesamiento matemático de datos, entre los que se puede destacar para el caso concreto las tecnologías avanzadas basadas en la idea de automatización, como deep learning o las redes neuronales artificiales. Estas últimas son técnicas basadas en la estructura biológica del cerebro humano, buscando la adaptación y reproducción de algunas de sus capacidades, 
tales como el proceso mental que hacen operadores judiciales, como los jueces al momento de tomar una decisión.

La aplicación de la inteligencia artificial en el campo de las decisiones judiciales suele denominarse "Inteligencia Artificial Judicial”, así, uno de los principales intereses se encuentra en los sistemas de inteligencia artificial que informa a los tribunales para la toma de decisiones en el ámbito penal (LINARES, 2018).

Para analizar los problemas jurídicos que pueden evidenciarse como consecuencia de la aplicación de la inteligencia artificial en las decisiones judiciales es necesario conocer a nivel general cómo se da el funcionamiento de estas herramientas. Lo primero que se debe tener en cuenta es que estas funcionan bajo el concepto de analítica predictiva, en donde se proveen patrones de conducta. Se trata de una herramienta basada en el análisis del big data singularizado, que se utiliza para intentar predecir decisiones futuras con base en el estudio sistemático de decisiones ya producidas (REYES, 2019).

Estos mecanismos que pueden ser utilizados en procesos judiciales para tomar las decisiones de los jueces se fundamentan en algoritmos de predicción implementados para la realización de acciones o recomendaciones, partiendo de un conjunto ya existente de datos, en virtud de patrones y probabilidades. Todo el contexto y la programación se realizan por seres humanos, quienes en virtud de la información que adecúan y los algoritmos que generan para relacionar las variables, determinan en su totalidad el comportamiento predictivo de la máquina. De esta manera, a partir de un grupo de datos se determinan patrones y relaciones entre variables que permitan establecer una predicción respecto a un determinado comportamiento futuro (LINARES, 2018).

La información que se utilice para la programación del sistema experto requiere de la colaboración conjunta del programador y los analistas jurídicos, esto ya que la calidad y cantidad de la información dependerá de lo que ambos consideren adecuado teniendo en cuenta la complejidad de la clase de problemas que se pretenden desarrollar, requiriendo una cantidad considerable de conocimiento sobre el área a tratar. Asimismo, cabe destacar que los sistemas expertos necesitan ser actualizados constantemente con nueva información, para que así puedan dar predicciones acordes con el estado de las cosas en un momento determinado (BADARÓ, IBAÑEZ \& AGÜERO, 2013).

En lo relacionado con las decisiones judiciales, la información con que los sistemas expertos deben programarse debe estar en total sintonía con el ordenamiento jurídico de un país, esto involucra la normativa en sus distintos niveles, es decir, leyes, decretos, reglamentos, circulares, entre otros; así como sentencias de las principales cortes y tribunales, los cuales permiten realizar un análisis completo al momento del problema objeto de estudio.

Estos mecanismos de analítica predictiva funcionan bajo sistemas jurídicos expertos, los cuales ayudan a los jueces a tomar sus decisiones planteando posibles soluciones a determinados asuntos jurídicos, aplicando el conocimiento experto que se tiene incorporado en su sistema a un determinado caso. 
Un sistema experto es un conjunto de procedimientos lógicos de inteligencia artificial que permiten que los computadores apoyen a los humanos en la tarea de analizar situaciones y adoptar decisiones. Son entonces bases de datos que cuentan no solo con conocimientos, sino también con un conjunto de reglas condicionales que unen conocimientos en forma operativa (DE TRAZEGNIES, 2013).

Por tanto, a nivel general, un sistema experto se diferencia de una base de datos en la cual los datos constan de manera estática, mientras que en los sistemas expertos los datos son dinámicos, así, no solo se limita a señalar la información, sino que además la vincula a los casos que pretenden tratarse; de esta manera, se procesa la información como lo haría un ser humano experto en esa materia (DE TRAZEGNIES, 2013).

Respecto al caso concreto, los sistemas de expertos jurídicos son los programas que están adecuados para actuar como operadores jurídicos inteligentes, teniendo como finalidad encontrar soluciones a los problemas jurídicos que se les presentan mediante la información que reposa en sus bases de datos.

Finalmente, se debe tener en cuenta que los sistemas jurídicos expertos necesitan, para dar su solución, tener contacto con el usuario, el cual en la mayoría de los casos se realiza mediante un sistema de preguntas en donde el sistema recibe la información necesaria para realizar el procesamiento adecuado que permita dar respuesta. Así, tal como lo señala Goretty Carolina Martínez (2018): "El sistema experto será capaz de asesorar al usuario siempre que este último interactúe con el programa proporcionándole directrices sobre las cuales ha de pronunciarse".

\section{Seguridad JURídica POR Medio de la CONFIANZA A LA IA}

La seguridad jurídica se entiende como:

La certeza sobre el ordenamiento jurídico aplicable y los intereses jurídicamente tutelados, interdicción de la arbitrariedad, de modo que permite en el ciudadano el nacimiento de una expectativa razonablemente fundada en cuál ha de ser la actuación del poder en la aplicación del Derecho (...). (RAMÍREZ, 2006)

Bajo ese panorama, frente a las decisiones judiciales, la seguridad jurídica se entiende como la certeza que la comunidad tiene de que los jueces han de decidir casos iguales de la misma forma. Así, en caso que las decisiones judiciales no fueran previsibles en este sentido, resultando las decisiones del pasado cambiante e inestable, los ciudadanos no podrían esperar que un asunto similar a otro, sometido a la jurisdicción se revuelva de forma semejante (CORTE CONSTITUCIONAL, 2001).

Tal como lo contempla la Corte Constitucional mediante la sentencia C-284 de 2015, para que haya seguridad jurídica en las decisiones judiciales se deben cumplir los siguientes deberes: 
1. las decisiones deben fundamentarse en las fuentes del Derecho previstas en el ordenamiento jurídico;

2. la aplicación del Derecho debe atender las reglas que la ley haya establecido para su interpretación;

3. las decisiones judiciales actuales deben guardar coherencia con las decisiones previas;

4. finalmente, el precedente judicial debe seguirse y la separación del mismo demanda cargas argumentativas especiales.

Se puede interpretar entonces que la seguridad jurídica tiene gran relación con la confianza que los individuos tienen en la administración de justicia, viéndose reflejada tal confianza en la garantía de que un caso similar a otro se decidirá en sentido análogo o teniendo en cuenta los criterios tomados por el primero.

En diferentes países de Latinoamérica, como ejemplo Colombia, no se puede desconocer que la rama judicial cuenta con gran congestión y poca celeridad, lo que ha influido notoriamente en una mala percepción por parte de la ciudadanía. Así, un estudio de la Facultad de Derecho de la Universidad Libre establece que la tramitología, la carga laboral en los juzgados y la impunidad son lo que ha generado la falta de credibilidad y la desconfianza de las personas en el sistema judicial colombiano; por tanto, la investigación señala que el $83 \%$ de las personas consultadas tiene una imagen negativa de la justicia (EL ESPECTADOR, 2018).

No solo la congestión ha llevado a una creciente desconfianza por la rama judicial, sino que además se deben sumar los escándalos ocurridos en las altas cortes, lo que genera que estas instituciones pierdan credibilidad, y que la seguridad jurídica se vea afectada.

Bajo este contexto, pese a los desafíos existentes con la aplicación de la inteligencia artificial en el mundo del Derecho, no se pueden desconocer las múltiples ventajas o beneficios que traería su adecuada aplicación. Así, cabe cuestionarse si la aplicación de la inteligencia artificial en las decisiones judiciales puede aumentar la confianza que la ciudadanía tiene en la administración de justicia, siendo esta una importante implicación para la rama judicial y las decisiones judiciales, toda vez que aumentaría la seguridad jurídica que se deposita en esta rama.

Muchas veces al momento de tomar una decisión en cuerpos colegiados, tales como las altas cortes, se evidencia que ante un mismo caso respecto del cual todos los magistrados tienen conocimiento de los mismos hechos, pueden presentarse desacuerdos y votaciones contrarias, lo que lleva a encaminar la decisión en algún sentido basada en creencias o pensamientos personales, lo que desdibuja la objetividad de la decisión fundamentada únicamente en las normas existentes y en las circunstancias aplicables a las mismas. 
Si bien la subjetividad que tienen los jueces al momento de realizar su valoración, es relevante siempre y cuando se realice con los factores y análisis adecuados; en la actualidad se evidencian dos problemáticas al respecto, la primera se encuentra relacionada con que muchas veces esta subjetividad necesaria termina implicando una ponderación de intereses particulares que no tiene cabida dentro de las decisiones judiciales; y por el otro, en muchas ocasiones el juez actúa de manera incluso más mecánica que lo que lo hace una máquina misma, así, termina replicando su comportamiento una vez vistas únicamente algunas circunstancias sistemáticas superficiales (PONS, 2018).

Una posible solución a la subjetividad excesiva de las decisiones judiciales se encamina a que estas decisiones sean fundadas en lo que señale un sistema experto jurídico que cuente con la información suficiente sobre la normativa de un país y la jurisprudencia que se ha emitido, para así analizar en sus bases de datos la información que contiene y brindar los elementos para tomar una decisión, o incluso la decisión misma.

Para tener confianza en las decisiones adoptadas por los sistemas expertos, se requiere interpretabilidad, lo cual permite conocer su funcionamiento interno para explicar los motivos por los cuales se sugiere tomar una determinada decisión. En esta medida, para ciertos casos y ciertas decisiones judiciales, no es suficiente únicamente la respuesta por parte del sistema experto, sino que es necesario conocer el camino utilizado para esa respuesta, lo cual es posible en virtud de la interpretabilidad y la transparencia (ASENCIO, 2018).

El conocer el procedimiento interno realizado por el sistema experto permite también aumentar la confianza y la seguridad que brindan, no solo a la ciudadanía en general sino a los jueces en particular; en la medida que habilita conocer el camino implementado y que quizá ellos hubieran podido utilizar para llegar a la misma decisión, pero en un menor tiempo y con mayor exactitud.

La toma de decisiones judiciales mediante la implementación de sistemas expertos puede aumentar la confianza que se tiene en la administración de justicia toda vez que un juez que es un experto humano que tiene los conocimientos sobre un tema para impartir una decisión al respecto se encuentra limitado por su propia naturaleza, naturaleza que implica el cansancio, fatiga, ignorancia, problemas familiares, de salud, y en general todas las características implícitas a nuestra condición (SAMACÁ, 2016), lo cual puede influir notablemente en las decisiones que se tomen, pudiendo incluso afectar la imparcialidad y con ello la seguridad jurídica misma.

Estos elementos ajenos al caso concreto no serían tenidos en cuenta al momento de tomar la decisión o de mostrar los elementos esenciales necesarios aplicables al caso concreto, si este proceso fuera realizado por un sistema jurídico experto que se fundamente únicamente en la normativa y jurisprudencia existente, abriendo así la posibilidad de garantizar decisiones más objetivas, predecibles, uniformes e incluso permitiendo mayor celeridad para las mismas.

$\mathrm{Al}$ programarse el sistema experto de una manera adecuada con los criterios jurídicos necesarios, se facilitaría la labor del juez y se lograría una mayor confianza por la población, 
ya que se tendría la seguridad de que es un tercero (el sistema experto) independiente, sin características humanas subjetivas el que está tomando la decisión en Derecho, lo cual permitiría tomar las decisiones manteniendo una total coherencia con la jurisprudencia previa, fomentando así la seguridad jurídica y confianza en la administración de justicia.

De esta manera, tal como lo señala el Consejo Superior de la Judicatura en Colombia (2013, p. 16), el aporte de las TIC en la justicia "ofrecería coherencia y seguridad jurídica en las decisiones de los jueces lo que desembocará en una mayor confianza y respeto por el sistema de administración de justicia, aplicando a situaciones iguales, decisiones iguales".

Es necesario tener claridad de que no se trata que los sistemas expertos sean quienes de manera exclusiva tomen la totalidad de las decisiones, sino que participen activamente en la toma de las mismas, indicando a los jueces la ruta o elementos en que la decisión se debe encaminar, aporte significativo que de igual manera permitiría aumentar la confianza y seguridad jurídica en la administración de justicia, en virtud de que sería la inteligencia artificial la que brinde los elementos a tomar en cuenta para la decisión con base en el precedente y en la normativa aplicable, pero sin descartar del todo la posibilidad de que los jueces en su libre albedrío analicen elementos adicionales y teniendo en cuenta la sana crítica estudien las pruebas para emitir su fallo.

Por tanto, una de las principales implicaciones que trae consigo la aplicación de la inteligencia artificial en las decisiones judiciales y la emisión de providencias, es el aumento de la confianza en la administración de justicia, lo que incrementaría a su vez la seguridad jurídica que las decisiones de los jueces generan.

\section{Costos vs. Descongestión}

La Constitución Política en su artículo 228 contempla la administración de justicia como una función pública, que busca garantizar los fines esenciales del Estado. En este sentido, la Corte Constitucional Colombiana (1997) desde tiempo atrás ha señalado que dicha función pública tiene naturaleza esencial, siendo uno de los pilares del Estado social democrático de derecho, por lo cual se debe cumplir de manera responsable, imparcial, independiente, ágil, eficiente y eficaz.

Adicionalmente, el acceso a la administración de justicia es catalogado como un derecho fundamental, el cual supone unas condiciones necesarias de manera conjunta para su ejercicio:

a) La libertad de acceso a la justicia, eliminando los obstáculos procesales que pudieran impedirlo; b) El derecho al debido proceso; c) El derecho a obtener una sentencia de fondo racional y justa, en un tiempo razonable y d) La garantía de que la sentencia se cumpla, es decir, la ejecutividad del fallo. (LONDOÑO, 2008, p. 389) 
Como se mencionó anteriormente, muchos sistemas judiciales en Latinoamérica, especialmente el colombiano, han tenido a lo largo del tiempo grandes problemas, los cuales afectan directamente el derecho al acceso a la administración de justicia, tales como la baja producción, congestión y mora judicial. La congestión judicial hace referencia al volumen de la demanda superior a la capacidad de respuesta de la rama judicial, y el atraso de la justicia entendido como la demora en la definición de la controversia jurídica que se somete a la consideración del juez, respecto del tiempo que la legislación contempla para la toma de una decisión (LONDOÑO, 2008).

A manera de ejemplo se establece que, en Colombia, para el año 2019, hubo un ingreso efectivo de 2.278.530 procesos, un inventario activo de 1.830 .958 procesos y un egreso efectivo de 1.854.505 procesos (corporación excelencia en la justicia, 2020). Estas cifras demuestran que los procesos que ya se encuentran en conocimiento de los jueces, sumado al número de procesos que día a día entran en los despachos, aumentan exponencialmente en comparación con los procesos que logran salir de la jurisdicción, lo cual congestiona el sistema y genera la mora judicial.

Cifras como las anteriores llevan a que un país como Colombia sea considerado como el sexto país con la justicia más lenta del mundo, de acuerdo con el reporte Doing Business 2018 del Banco Mundial, contando únicamente con 11 funcionarios judiciales por cada 100.000 habitantes (ASOSEC, 2018).

En este contexto, la congestión judicial es una de las principales problemáticas que afecta la administración de justicia en el país, haciéndola más lenta, menos accesible, más costosa y generando un impacto negativo en la sociedad, toda vez que se tiene una percepción de impunidad (TIQUE, 2018).

Teniendo como base esta problemática de la rama judicial en relación a la congestión existente, es dable cuestionarse si los costos en que se incurrirían para implementar sistemas expertos jurídicos en Colombia serían justificables o no con la subsiguiente descongestión del sistema judicial.

Como se ha indicado, actualmente se transita por una nueva revolución que se vincula con diferentes fenómenos, siendo el más disruptivo el desarrollo de la inteligencia artificial. Esta "Cuarta revolución Industrial" se fundamenta en dos factores: la capacidad de almacenamiento y la velocidad de procesamiento de la información y de los datos. En esta medida y dada la cantidad de información que se presenta, como lo puede ser para el caso concreto la gran cantidad de expedientes existentes y de precedentes judiciales, se genera que este proceso no logre desarrollarse de manera suficientemente eficiente por personas; por ende, la inteligencia artificial permite que se logre igualar o superar en gran medida las

1 Se ha denominado “Cuarta Revolución Industrial” con base en lo señalado tanto por el Foro Económico Mundial como por la Organización Internacional del Trabajo. 
capacidades cognitivas a través de la velocidad en que se logra procesar los datos y la información (CORVALÁN, 2018).

Una herramienta de inteligencia artificial entrenada adecuadamente, con acceso al flujo informático, simplifica y facilita sustancialmente las actividades tanto de entidades privadas como públicas, incluyendo las ramas del poder público, abriendo la posibilidad de obtener resultados que serían imposibles de lograr con el trabajo únicamente del ser humano. La agilidad de estos sistemas se debe a la optimización de la información y la utilización de la misma para resolver cuestiones que requerían anteriormente múltiples pasos, procedimientos y etapas (CORVALÁN, 2018).

Teniendo en cuenta los beneficios que podrían generarse con la implementación de la inteligencia artificial para la toma de las decisiones en la rama judicial, y que se ajusta a los cambios que se pretenden hacer en la revolución tecnológica, es necesario analizar un tema relevante para que se pueda dar su utilización, como lo es el presupuesto destinado a los costos que compone la implementación de sistemas expertos.

Si bien determinar el costo que tendría la implementación de un sistema de expertos en la rama judicial es una tarea conjunta que se debe realizar entre expertos de diversas ramas, el objetivo que se debe tener en cuenta en materia económica es realizar un balance entre el esfuerzo presupuestario del Estado que se tiene en personal y los consecuentes protocolos de trabajo tradicional en la resolución de procesos, y contrastarlo con los efectos de la aplicación de la Inteligencia Artificial en modernizar la administración de justicia (ROMINA, s.f.).

Para este análisis y a modo de ejemplo, es importante tener en cuenta que el presupuesto de la rama judicial en Colombia para el año 2020 se divide en presupuesto de funcionamiento y presupuesto de inversión, dentro del cual se encuentra la subpartida 2701 relacionada con el "Mejoramiento de las competencias de la administración de justicia”. Así, es necesario un análisis profundo de los elementos que integran esta subpartida, para determinar si fuera posible la aplicación de la inteligencia artificial en este país teniendo en cuenta el presupuesto general del mismo (MINISTERIO DE HACIENDA Y CRÉDITO PÚBLICO, 2019).

Como lo señala Garmendia Romina (s.f.), para analizar si vale la pena invertir en sistemas de expertos para la toma de decisiones judiciales, se deben tener en cuenta aspectos como: i) la obligación del Estado de brindar, para derechos fundamentales como el acceso a la administración de justicia, el máximo posible de sus recursos disponibles; ii) se debe compensar el impacto económico de las herramientas tecnológicas con el impacto económico de la subsistencia del sistema judicial tradicional carente de inteligencia artificial; iii) analizar dentro de tal compensación en qué medida se agilizaría el proceso por la utilización de la inteligencia artificial; y iv) la identificación de los factores condicionantes de la atribución de recursos a la implementación de la IA.

Especial énfasis debe realizarse en los puntos ii) y iii) anteriormente mencionados. En primer lugar, es de suma importancia determinar las diferencias presupuestarias existentes entre una justicia que implemente sistemas expertos y aquella que no, esto ya que el no 
implementar esta clase de sistemas genera que sea igualmente necesario la ejecución de otros mecanismos para mitigar el problema que se continuaría presentando, el cual, dadas sus dimensiones no se soluciona únicamente aumentando el número de jueces, sino que dadas las proporciones del mismo, requiere una suma de esfuerzos y medidas que pueden resultar igualmente onerosas y representar gastos periódicos y a largo plazo para la rama.

Asimismo, el iii) punto relacionado con la agilización de los procesos es relevante toda vez que, como se ha expuesto, la implementación de sistemas expertos que participen en la toma de decisiones, implica la posibilidad de tener fallos judiciales en menor tiempo y con ello una mayor agilidad en el sistema, lo cual beneficia no solo a la rama como entidad, sino a la ciudadanía en general ya que tendría una administración de justicia más expedita y con ello una mayor protección a su derecho fundamental.

De esta manera, es importante realizar una ponderación entre los intereses que se tienen y las obligaciones que tiene el Estado de proteger derechos, teniendo en cuenta que la protección del derecho al acceso a la justicia no se limita a tal, sino que este involucra el ejercicio de otros derechos que también pueden considerarse fundamentales. Por tanto, una justicia eficiente permite que las personas puedan gozar de otros derechos afectados, lo que podría justificar los costos que un sistema con estas características requiera.

Cabe destacar que la aplicación de la inteligencia artificial en la rama judicial no necesariamente se debe limitar a sistemas expertos que ayuden a los jueces al momento de fallar, se pueden implementar otras herramientas, como machine learning, que permitan facilitar otras etapas del proceso, ayudando en tareas fáciles dentro de la obligación de administrar justicia $y$, por tanto, pueden generar menores costos que la implementación inicial de un sistema de expertos. Así, lo relevante más que el mecanismo que se utilice es la viabilidad y necesidad de buscar alternativas para agilizar la justicia, dentro de las cuales la inteligencia artificial se presenta como una importante opción.

La implementación de la inteligencia artificial en el Derecho propende por la agilización de procesos mediante la búsqueda y la implementación de la normativa adecuada y del precedente judicial aplicable al caso concreto, razón por la cual las labores del juez podrían realizarse de manera más expedita, ahorrado el tiempo no solo del juez, sino de cualquier funcionario de un despacho a la hora de realizar la labor investigativa.

Adicionalmente, la implementación de la inteligencia artificial para la toma de decisiones permitiría también conocer de manera más expedita los hechos y problema jurídico de cada controversia, las pruebas con que se cuenta y las que podrían requerirse, para que sea el juez quien con las pruebas lo suficientemente organizadas y determinadas realice su estudio y evaluación con base en la sana crítica, siendo él mismo quien profiera los fallos con base en sus consideraciones particulares pero con los elementos objetivos de análisis determinados por el sistema experto.

Como ejemplo de la funcionalidad para la descongestión judicial que trae consigo la aplicación de la inteligencia artificial se puede tener en cuenta un país como Australia, que para 
el año 2018 fue el tercer país con justicia más rápida en el mundo; asimismo Estados Unidos ocupa el decimosexto puesto, destacándose ambos países a nivel mundial por ser pioneros en la aplicación de las nuevas tecnologías para la administración de justicia (NARVÁEZ, 2018). Otro ejemplo de la implementación de la inteligencia artificial en la administración de Justicia es Estonia y China, en donde algoritmos podrían tomar decisiones en primera instancia, buscando con ello el gobierno agilizar la justicia de procesos sencillos para que los jueces tengan el conocimiento de los procesos de mayor envergadura.

Desarrollando lo anterior, en países como Estonia se ha propuesto que sea la inteligencia artificial la encargada de analizar gran cantidad de documentos legales y demás información relevante para la toma de decisiones en un determinado caso, sin embargo, y tal como se propone en este texto, sería un juez humano quien finalmente tomara la decisión final. Así, el Ministerio de Justicia de este país consideró esta solución como una opción adecuada para aligerar la carga y el tiempo en la resolución de disputas legales sencillas (GESTIÓN, 2019).

La aplicación de este proyecto en Estonia se desarrollaría así: las partes serían las encargadas de cargar sus documentos e información relevante del caso en una plataforma, en donde los sistemas de inteligencia artificial estudiarían la documentación y propondrían una resolución que podría ser apelada por un juez humano (THE TECHNOLAWGIST, 2019).

Si bien en Estonia se tiene como iniciativa, en la actualidad China ya cuenta con la implementación de robots en los juzgados. El primer asistente de inteligencia artificial en esta área utilizado en China se denomina Xiao Fa, el cual brinda un asesoramiento legal a los ciudadanos chinos en el tribunal de Beijing, así, explica y aclara conceptos jurídicos; adicionalmente, colabora con los propios funcionarios en la recopilación de sentencias, revisar historial de fallos, comparar leyes, entre otras labores (WEI, 2019). Posteriormente se realizó el primer tribunal cibernético en la ciudad china de Hengezhou en agosto de 2017, abriendo paso a los llamados tribunales de internet que son competentes en asuntos como operaciones en red, comercio electrónico y propiedad intelectual.

Asimismo, se ha introducido un software que utiliza IA para ayudar en la toma de decisiones de procedimientos legales ordinarios, como la apertura y el procesamiento de casos, el cual ayuda a los jueces humanos en cuestiones repetitivas, permitiendo que se centren en cuestiones jurídicas de fondo. El sistema se comunica con los ciudadanos mediante una interfaz diseñada como una imagen femenina en pantalla, guiando para solicitar casos y hacer las transacciones mediante internet (TRT, 2020).

Se evidencia pues que la innovación de la inteligencia artificial en el ámbito de lo público, especialmente en la administración de justicia, implica un salto en relación a la velocidad y la precisión de la labor de los jueces, para prestar con ello un mejor servicio de la justicia (CORVALÁN, 2018).

Pese a esta innovación y los consecuentes beneficios, el costo sigue siendo uno de los principales inhibidores para la adopción de estas tecnologías, no obstante, este problema 
podría zanjarse mediante precios granulares por parte de los proveedores, basados en el consumo y licencias flexibles de ofertas de IA a nivel nacional. En esta medida, los proveedores de esta tecnología deben proporcionar soluciones integradas de hardware/software optimizada para la IA, lo cual permitiría alivianar las complejidades de implementación y administración, permitiendo precios bajo control y accesibles (JYOTI, 2019).

Si bien se requiere un estudio minucioso al respecto que permita determinar hasta qué punto es posible invertir parte del presupuesto de la rama judicial en la implementación de sistemas expertos, es dable señalar que se justifican los costos que implican la adaptación de la inteligencia artificial en la rama, con la consecuente descongestión judicial que traería consigo.

Esto ya que, como se ha explicado a lo largo de este texto, traería beneficios para la seguridad jurídica del país y el aumento de la confianza, además de garantizar derechos fundamentales con mayor agilidad.

Adicionalmente, como lo señala Marco Ribas (2019), Country Managing Director de Accenture Colombia, la inteligencia artificial tiene el potencial de doblar el crecimiento de las economías desarrolladas desde la fecha hasta el año 2035, adoptándose modelos híbridos con los capitales de inversión y humano, así, la IA potencializará las habilidades y actividades humanas, no solo en la toma de decisiones de los jueces, sino en todo el proceso judicial con su adecuada implementación en las diversas fases del proceso en donde tenga oportunidad de ser aplicada.

Asimismo, se refuerza la idea de una justificación de los costos de adaptación de la inteligencia artificial en la rama judicial teniendo en cuenta estudios como el realizado por Accenture en el año 2017, que demuestra que en el caso específico de Colombia un desarrollo correcto de la IA podría significar un crecimiento adicional de 0,8 puntos porcentuales para el año 2035, y el Valor Agregado Bruto (VAB) del país en US\$ 78.000 millones en el mismo periodo (RIBAS, 2019).

Otro aspecto importante a tener en cuenta como evidencia práctica para conocer la eficiencia que tiene la aplicación de la inteligencia artificial en las decisiones judiciales se encuentra en el caso Prometea, expuesto anteriormente, en donde con base en un estudio publicado por el BID en el 2018 los seres humanos tardan aproximadamente 172 días en resolver 1.000 casos judiciales de baja complejidad; empero, Prometea puede dar respuesta a esos 1.000 casos en 42 días sin que sea necesaria la revisión gramatical y ortográfica posterior, teniendo importantes porcentajes de eficiencia que sobrepasan en la mayoría de los casos el $300 \%$, tal como se evidencia en la Tabla 1. 
TABLA 1 - DÍAS DETRABAJO PARA REALIZAR I.000 EXPEDIENTES / PROCESOS

\begin{tabular}{|c|c|c|c|c|}
\hline & & SIN PROMETEA & CON PROMETEA & $\begin{array}{l}\text { PORCENTAJE } \\
\text { DE EFICIENCIA }\end{array}$ \\
\hline \multirow{4}{*}{$\begin{array}{r}\text { FISCALÍA GENERAL ADJUNTA } \\
\text { EN LO CONTENCIOSO, } \\
\text { ADMINISTRATIVO Y } \\
\text { TRIBUTARIO DE CABA }\end{array}$} & AMPARO HABITACIONAL - NO AUTOSUFICIENTE & 160 & 38 & 323 \\
\hline & AMPARO HABITACIONAL - PERSONA CON DISCAPACIDAD & 174 & 45 & 289 \\
\hline & AMPARO HABITACIONAL - PERSONA SOLA & 164 & 45 & 263 \\
\hline & AMPARO HABITACIONAL - CITACIÓN DE TERCERO & 190 & 42 & 357 \\
\hline \multirow{3}{*}{$\begin{array}{r}\text { FISCALÍA PENAL, } \\
\text { CONTRAVENCIONAL Y DE } \\
\text { FALTAS NO } 12 \text { DE CABA }\end{array}$} & PROCESO DE PROBATION & 110 & 26 & 318 \\
\hline & PROCESO DE JUICIO ABREVIADO & 145 & 33 & 336 \\
\hline & PROCESO DE REQUERIMIENTO A JUICIO & 167 & 38 & 338 \\
\hline
\end{tabular}

Fuente: ESTEVADEORDAL et al. (2018, p. 262).

Los resultados económicos de la relación costo/beneficio no son lineales, sin que sea posible establecer de manera determinista que será siempre positiva la relación costo/beneficio en todos los casos de implementación de inteligencia artificial en las decisiones judiciales, toda vez que se depende de un factor de probabilidad y madurez de los modelos que hacen el análisis de la información. Sin embargo, se evidencia que si bien se podrían generar altos costos iniciales con la aplicación de la inteligencia artificial en la rama judicial, presentándose variaciones dependiendo la herramienta utilizada, es una implementación que en el tiempo generaría importantes impactos positivos no solo dentro del acceso a la justicia y en la eficiencia en su desarrollo y respuesta, sino a nivel del crecimiento del país en distintas áreas y que en el tiempo vería retribuida la inversión realizada.

\section{LA RESPONSABILIDAD DENTRO DE LA INTELIGENCIA ARTIFICIAL}

La inteligencia artificial aplicada para ayudar al sistema judicial a tomar sus decisiones funciona a través de sistemas de expertos jurídicos, los cuales se desarrollan mediante la programación de algoritmos de predicción partiendo de un conjunto ya existente de datos. Tal programación es realizada por seres humanos, diseñadores que adecúan los algoritmos mediante variables y patrones de probabilidad.

Si bien se ha reiterado en que la idea de implementar estos sistemas de expertos no es que sean estas máquinas quienes tomen en su totalidad la decisión que las partes han de tener que acatar, sí se pretende que estas herramientas brinden a los jueces los elementos necesarios que debe tener su decisión, mediante el análisis de big data, que para los procesos judiciales consistiría en la innumerable cantidad de normativa y jurisprudencia, garantizando con ello la implementación de la norma adecuada y el seguimiento del precedente. Así, con tal 
información, es el juez quien analiza la posible sentencia e investigación realizada por el sistema, y en caso de considerarlo aplicable al caso falla en tal sentido.

Teniendo en cuenta la gran influencia que tendría el sistema experto al interior del proceso judicial y de la toma de decisiones, cabe preguntarse cuál sería el nivel de responsabilidad de su diseñador ante un funcionamiento incorrecto del mismo, en caso que se considere que tiene tal responsabilidad. Es necesario realizar esta pregunta ya que, como se indicó, es el juez quien finalmente toma la decisión en un determinado caso, así, ante una decisión que se podría considerar como arbitraria o injusta se debe determinar en quién podría recaer tal responsabilidad.

Para analizar la responsabilidad en la toma de decisiones de los sistemas de inteligencia artificial se requiere transparencia, así, los sistemas de expertos deben tener la posibilidad de explicar sus acciones a las personas, en este caso a los jueces, y demostrar por qué se tomó esa decisión (BOTTI, 2019). Asimismo, se trata de una cuestión compleja al tener en cuenta el nivel de autonomía de los sistemas expertos, ya que podría dejar de tratarse de una cuestión doctrinal y enmarcarse en el marco de lo probatorio, lo que lleva a rastrear cadenas de auditoría para determinar la responsabilidad entre programadores, diseñadores e inclusive el mismo juez (CABALLERO, 2019).

En primer lugar, y antes de hablar sobre la responsabilidad o no que puede llegar a tener el diseñador y el programador del sistema experto, se debe tener en cuenta como lo ha establecido la Montreal Declaration for a Responsible Development of Artificial Intelligence (2018), que la inteligencia artificial no debe contribuir a que se busque disminuir la responsabilidad de las personas en la toma de decisiones, esto ya que:

1. Solo los seres humanos pueden ser responsables de las decisiones que provienen de las recomendaciones formuladas por herramientas de inteligencia artificial y de las acciones que de ellas se originen.

2. En la totalidad de las áreas donde se debe tomar una decisión que puede afectar la vida, calidad o reputación de una persona, la decisión final debe ser tomada por un ser humano, siendo esta una decisión libre e informada.

3. Las decisiones que atenten contra la vida deben ser tomadas siempre por seres humanos, sin que se pueda transferir la responsabilidad de tal decisión a la inteligencia artificial.

4. Las personas que autorizan a las herramientas de inteligencia artificial a cometer delitos actúan con negligencia al permitir que la IA los cometa, así, son los responsables de tal delito.

5. Cuando la inteligencia artificial es confiable y se ha utilizado según lo previsto, pero aun así genera daños, no es razonable culpar a las personas involucradas en su desarrollo o uso. 
Montreal Declaration for a Responsible Development of Artificial Intelligence es un conjunto de pautas éticas para el desarrollo de la inteligencia artificial, el cual propone para su implementación los siguientes principios:

1. Principio de bienestar: en virtud del cual el desarrollo y uso de los sistemas de IA permiten el crecimiento del bienestar de todos los seres "sintientes".

2. Principio de autonomía: los sistemas de IA deben desarrollarse y utilizarse respetando la autonomía de las personas y teniendo como objetivo aumentar el control de las personas sobre su vida y su entorno.

3. Protección de la privacidad y la intimidad: la privacidad y la intimidad deben estar protegidas de intrusiones de sistemas de inteligencia artificial y de los sistemas de adquisición y archivo de datos.

4. Principio de solidaridad: el desarrollo de inteligencia artificial debe ser compatible con el mantenimiento de los lazos de solidaridad entre las personas y generaciones.

5. Participación democrática: los sistemas de inteligencia artificial deben cumplir con criterios de inteligibilidad, justificación y accesibilidad, así, deben estar sometidos al escrutinio, debate y control democrático.

6. Principio de equidad: el desarrollo y el uso de los sistemas de inteligencia artificial deben contribuir a la creación de una sociedad justa y equitativa.

7. Inclusión y diversidad: el desarrollo y el uso de la inteligencia artificial deben ser compatibles con el mantenimiento de la diversidad social y cultural, y no deben restringir el alcance de las opciones de estilo de vida y experiencia personal.

8. Principio de prudencia: toda persona involucrada en el desarrollo de IA debe tener precauciones de manera anticipada para prever dentro de lo posible las medidas adversas del uso de sistemas de inteligencia artificial, tomando medidas apropiadas para evitarlas.

9. Principio de responsabilidad: el desarrollo y el uso de sistemas de inteligencia artificial no deben contribuir a disminuir la responsabilidad de los seres humanos en la toma de decisores.

10. Desarrollo sostenible: el desarrollo y el uso de sistemas de inteligencia artificial deben llevarse a cabo para garantizar una fuerte sostenibilidad ambiental del planeta (UNIVERSITÉ DE MONTRÉAL, s.f.). 
Con base en lo anterior, es necesario establecer que no es dable atribuir responsabilidad alguna al sistema experto que se encarga de tomar la decisión, toda vez que finalmente la decisión está siendo tomada por un ser humano quien es el que en última instancia decide adoptarla o no. Así, se debe tener siempre presente que la inteligencia artificial es humana, ya que la han creado y programado seres humanos, así tenga incluso la capacidad de "aprender" de los datos que recopila, pero como tal no dicta las sentencias, así únicamente ayuda a dictarlas (PONS, 2018).

Pese a lo anterior, existen autores, como López de Mántaras (2015), que proponen distinguir entre la IA débil y una IA fuerte, distinción que fue introducida originalmente en el año 1980 por el filósofo John Searle. La IA débil permitiría diseñar y programar ordenadores capaces de realizar tareas de forma inteligente, mientras que la IA fuerte permite replicar en máquinas la inteligencia humana, así, la IA fuerte estaría dotada de una inteligencia de tipo general. Esta inteligencia general, la cual está presente en los seres humanos, sería la condición suficiente para generar que un dispositivo actúe en forma autónoma, no solo automática, lo que generaría la posibilidad de vislumbrar una responsabilidad en esta clase de IA; responsabilidad que sería independiente de la de los seres humanos que participaron en su proceso de creación (MARÍN, 2019).

No obstante, lo relacionado con la IA fuerte resulta complejo toda vez que en la actualidad no es claro que sea posible la creación de máquinas con inteligencia de tipo general, toda vez que se conoce que la complejidad del cerebro humano es prácticamente imposible de replicar (LÓPEZ DE MÁNTARAS, 2015). En este sentido, y como se ha señalado, no es viable en el estado de las cosas atribuirle la responsabilidad de una decisión al sistema experto jurídico basado en inteligencia artificial, toda vez que este no toma las decisiones de manera autónoma, sino que establece una respuesta basando esta decisión en la programación con que cuenta.

Por tanto, no es dable equiparar conceptos de inteligencia, comprensión o aprendizaje en cuanto tal, propios de los seres humanos, en los sistemas de expertos; ya que estos actúan únicamente de manera automática con la información pre establecida con que cuentan, a través de la cual tienen la capacidad de realizar tareas en entornos completos sin intervención humana, pero sin contar propiamente con un análisis que se encuentre por fuera de su programación.

Bajo este panorama, continúa la pregunta de quién sería el responsable de los daños producidos en caso que los dispositivos de inteligencia artificial operen erróneamente o tomen una decisión en este caso judicial en forma autónoma que genere un perjuicio.

A nivel general podría decirse que cualquier daño que un sistema inteligente ocasione es responsabilidad de las personas encargadas del diseño y programación de los algoritmos. La responsabilidad de los diseñadores y programadores de herramientas de inteligencia artificial puede analizarse desde dos perspectivas: una responsabilidad positiva y una responsabilidad negativa. 
La responsabilidad activa o positiva se concentra en lo que los expertos en inteligencia artificial deben hacer, y cómo garantizar la seguridad de las herramientas de inteligencia artificial que realizan a través de medios técnicos. Por su parte, la responsabilidad negativa se centra en cómo los expertos en IA deberían asumir la responsabilidad cuando la inteligencia artificial genera un impacto negativo o graves consecuencias. Desde la perspectiva de la responsabilidad positiva, los expertos no pueden perseguir beneficios económicos o atender ciegamente las necesidades de un cliente en el proceso de investigación y desarrollo. Asimismo, desde la perspectiva de la responsabilidad negativa, cuando el sistema de inteligencia artificial presenta errores, los expertos deben asumir tal responsabilidad, en lugar de buscar alternativas que culpen al sistema de IA por su complejidad e incertidumbre (MAN QI \& WENZHANG, 2018).

De esta manera, como se ha indicado, el problema sobre la seguridad y responsabilidad en la inteligencia artificial no radica en la tecnología como tal, sino que debe estudiarse en relación a los diseñadores y creadores de la misma, en donde se debe propender por garantizar la seguridad de tales sistemas al momento de su creación, buscando realizar verdaderos aportes a la ciencia y en este caso al mundo del Derecho más que el seguimiento y consecución de intereses particulares, razón por la cual, en caso de errores en tal programación o en el sistema mismo, debiendo haber seguido unos patrones, se debe asumir la responsabilidad por tal yerro, entrándose a estudiar qué clase de responsabilidad sería en los diferentes eventos que pueden generarse.

Una problemática que se presenta es la que se ha denominado por algunos autores como "the problem of many hands", siendo el problema de la atribución y distribución de la responsabilidad, en donde para la creación de las herramientas tecnológicas hay muchas personas involucradas, lo que hace difícil encontrar al individuo responsable, en caso que solo haya uno, o responsabilizar a cualquier individuo toda vez que puede haber un número plural de personas involucradas (COECKELBERGH, 2019).

Como respuesta a esta problemática, se ha propuesto el concepto de "Distributed responsability", el cual establece que:

The effects of decisions or actions based on AI are often the result of countless interactions among many actors, including designers, developers, users, software, and hardware.... With distributed agency comes distributed responsibility. (TADDEO \& FLORIDI, 2018, p. 751)

Si bien en la teoría esta es una buena solución, como lo señala Coeckelbergh (2019), en la práctica no se resuelve el interrogante de cómo distribuir la responsabilidad, dado que no necesariamente se conoce el alcance de todas las contribuciones y participaciones dentro la creación del sistema experto jurídico. Asimismo, se presentan participaciones en diferentes momentos de la creación, por tanto, la responsabilidad no es solo cuestión de personas sino 
de interfaces que se interrelacionan entre sí, así, no necesariamente la IA es la que causa el problema, puede tratarse de otro componente de la máquina, dentro de su sistema tecnológico que llevó a la mala decisión o al error, pero no como tal la IA.

Pese a la posibilidad de distribución de responsabilidad entre los creadores, diseñadores y programadores, de manera proporcional a su participación en la creación de los sistemas expertos que tomarán las decisiones en los sistemas judiciales, se ha reiterado a lo largo de este texto que el fin de la inteligencia artificial que se podría implementar y se propone, en las decisiones tomadas por los jueces, no es llegar a sustituir el papel del juez al momento de decidir, sino por el contrario otorgarle las bases suficientes para que este se fundamente en tal sistema al momento de tomar su decisión.

Por ello, se debe tener en cuenta que la inteligencia artificial no puede ofrecer siempre soluciones correctas y de aplicación definitiva en las decisiones judiciales, sino que se encarga de brindar opciones diferentes basadas en procesos cognitivos, así, es el juez el responsable de apoyarse en la opinión que considere más adecuada.

Si bien los sistemas expertos jurídicos encargados de participar en el proceso de las decisiones judiciales, únicamente brindan herramientas para decidir, pueden existir otros mecanismos de inteligencia artificial e incluso otras tecnologías, como los contratos inteligentes, que en efecto podrían llegar a suprimir la intervención humana. Estas herramientas son aplicables en el mundo del Derecho e incluso dentro de la rama judicial para aquellos procesos donde el riesgo ético y de responsabilidad es mínimo, generando esta intervención tecnológica importantes cuestionamientos sobre la eliminación de la participación del ser humano.

En este contexto, se puede señalar que ante un error en una determinada decisión judicial que se basó en sistemas de inteligencia artificial, la responsabilidad de tal yerro no puede recaer en el programador, o diseñador ni mucho menos en el sistema experto mismo. Esto ya que la responsabilidad del diseñador llegaría únicamente hasta la teoría de responsabilidad por producto defectuoso que se tiene en la actualidad y la garantía misma, pero no por las consecuencias de la decisión que se tome ya que esta responsabilidad debe recaer sobre el juez, quien finalmente toma su decisión con base en su sana crítica, teniendo la potestad de evaluar o no el proyecto de decisión del sistema experto y tomar los elementos que este brinda para fundamentar su decisión.

Así, si en virtud del principio de transparencia ya expuesto, el sistema de inteligencia artificial expone los elementos y bases en que se fundamentó para alcanzar una determinada decisión, pero si el resultado de esta no es el que podía esperarse, no puede culparse al diseñador de la responsabilidad y consecuencias de tal decisión, ya que este cumplió su labor al programar al sistema de experto para conocer las normas y la jurisprudencia que podría aplicarse, pero es el juez quien, tomando estos sustentos, debe determinar si se pueden enmarcar en cada caso concreto.

Si bien se puede resolver entonces el interrogante sobre la responsabilidad de una decisión problemática por parte de un sistema jurídico experto, queda abierto el cuestionamiento 
en relación de hasta qué punto el operador jurídico puede llegar a confiar en tal sistema experto para la toma de las decisiones. Esto ya que el sistema experto es quien tendría en su ordenador toda la big data normativa de un territorio, lo cual es lo que impulsa a encaminarse hacia una predicción que el juez podría llegar a ver con desconfianza en su objetivo de una decisión acertada.

Finalmente, independientemente de los niveles de responsabilidad de quienes participan en el proceso, se ha señalado que, buscando no perder el control de la inteligencia artificial que se desarrolla, esta debe diseñarse de manera transparente, cuyos sistemas sean de cierta forma compatibles con nuestros valores morales, sociales y culturales en áreas como la seguridad, sostenibilidad, democracia, participación, seguridad, transparencia, rendición de cuentas, propiedades y funciones. Buscando el cumplimiento de estos parámetros surge la inteligencia artificial responsable, que consiste en una inteligencia artificial de confianza que se basa en valores éticos y sociales con un enfoque centrado netamente en el ser humano (BOTTI, 2019).

De esta manera, y en sintonía con la responsabilidad positiva de la que se hablaba anteriormente, tienen especial relevancia en el tema de la inteligencia artificial los debates en torno a la responsabilidad y la ética de la misma. Un ejemplo de lo anterior está dado por la resolución adoptada por American Bar Association que insta a los tribunales y abogados a abordar los problemas éticos y legales relacionados con el uso de la inteligencia artificial en la práctica del Derecho (NEWSWIRES, 2020).

Asimismo, se ha establecido que, en vista del importante desarrollo de la inteligencia artificial, es necesario establecer principios y pautas para que esta tecnología se emplee de manera responsable y segura, lo cual puede contribuir a potenciar los beneficios que se pueden obtener de ella así como a minimizar los riesgos que su uso implica. Dentro de los principios éticos que se han enunciado, a modo de ejemplo se encuentran: (i) respeto de la autonomía humana; (ii) transparencia; (iii) responsabilidad y rendición de cuentas; (iv) robustez y seguridad; y (v) justicia y no discriminación. Estos principios son de especial relevancia durante el diseño, no obstante, también deben aplicarse en la etapa de desarrollo, introducción y adopción de la tecnología (MARÍN, 2019).

Si bien tener en cuenta los criterios éticos y principios esenciales durante el diseño es necesario, a esto debe acompañarse otros mecanismos que permitan a los diferentes sectores que tienen interés incorporar los principios y normas de funcionamiento necesarias para la correcta aplicación de estas herramientas tecnológicas (MARÍN, 2019).

Los debates éticos que se generan en torno a la aplicación de la inteligencia artificial pueden tener como origen el instinto del ser humano en mantener su profesión, así, los profesionales de las leyes buscan que estas herramientas de inteligencia artificial tengan límites y restricciones claras para evitar así una posible intromisión en la totalidad de las áreas del Derecho que afecte el desempeño de sus funciones y los empleos.

No obstante, no se pueden desconocer problemáticas éticas ya existentes en relación a la aplicación de la inteligencia artificial en las decisiones judiciales, tales como el sesgo o 
discriminación proveniente de la propia información que nutre el sistema. En este sentido, los sistemas que implementan inteligencia artificial, especialmente los que utilizan grandes cantidades de datos, pueden llegar a contar en su programación con algún tipo de sesgo o prejuicio que tenga como consecuencia que sus decisiones o conclusiones sean parciales o injustas (MITTELSTADT et al., 2016, p. 7).

Como ejemplo de esta problemática dentro de un panorama general, se tienen casos como el algoritmo de contratación de Amazon, el cual discriminaba mujeres solo por el hecho de serlo, razón por la cual perdió credibilidad por los ejecutivos de la compañía por la pérdida de confianza frente al público (RODRÍGUEZ, 2019). Otro ejemplo reconocido es el relacionado con el caso State vs. Loomis, en donde una investigación sobre el algoritmo inteligente que realizaba predicciones sobre la reincidencia en el ámbito delictivo estableció que solo el $20 \%$ de las personas predichas por cometer el crimen lo realizó; no obstante, se obtuvo una mayor tasa de predicción y de falsos positivos en el caso de afroamericanos, siendo etiquetados más a menudo como de alto riesgo en comparación con los acusados de otras razas (CORVALÁN, 2018).

Como se ha sostenido en este texto, las responsabilidades de tal discriminación no provienen propiamente de los sistemas externos, sino que se originan en la información con que se haya programado el sistema, así, tales sesgos tendrían origen en concepciones discriminatorias del propio programador. También puede presentarse el sesgo por patrones históricos de discriminación, en donde las máquinas aprenden teniendo en cuenta estadísticas anteriores. De esta manera, como lo indican autores como Juan Gustavo Corvalán (2018), tanto el diseño como la implementación de las herramientas de inteligencia artificial deben respetar principios como el de no discriminación, el cual impide que estos sistemas procesen información bajo sesgos por motivos de raza, color, sexo, idioma, o cualquier otra clase de condición.

Adicional al problema ético de discriminación al que se ha hecho referencia, es necesario exponer otros dilemas que se han presentado y respecto de los cuales es necesario adoptar las políticas adecuadas y las medidas de prevención suficientes, el primero relacionado con la invasión de entornos, toda vez pueden presentarse ataques o envenenamiento de información, así como exposición de fallas en el diseño de objetivos. Asimismo, pueden presentarse problemas con respecto a la intimidad, aprovechándose de vulnerabilidades en relación a la información, así como el uso malicioso que se le puede dar a estas herramientas (GONZÁLEZ \& MARTÍNEZ, 2020).

Ante las distintas problemáticas éticas y morales que se pueden llegar a presentar con respecto a los sistemas de inteligencia artificial, autores como Bostrom y Yudkowsky (2011), citados por David Álvaro Pascual (2017), señalan se deben tener en cuentas medidas como:

a) control e inspección de los sistemas mediante expertos humanos que puedan auditar o inspeccionar el correcto funcionamiento de los sistemas de manera periódica; 
b) los algoritmos pueden ser susceptibles de inspección para ser periódicamente vigilados;

c) en materia jurídica sería el equivalente al principio de legalidad en las manifestaciones, o al de transparencia, en donde todos los ciudadanos tengan el conocimiento de los criterios mediante los cuales los sistemas actúan y tomas sus decisiones, teniendo así una mayor seguridad;

d) los algoritmos deben ser inexpugnables ante manipulaciones, de esta manera, deben ser incorruptibles, lo más seguros posibles ante injerencias con fines fraudulentos; y

e) se deben establecer parámetros para determinar los responsables de posibles fallas.

Así, para que las herramientas de inteligencia artificial puedan ser implementadas en diferentes áreas del Derecho, principalmente en lo relacionado con la toma de decisiones, es necesario la toma de medidas adecuadas que busquen disminuir posibles problemas éticos que pueden tener importancias repercusiones en la sociedad.

\section{CONCLUSIONES}

Con lo hasta acá expuesto se puede concluir en primer lugar que, como se ha insistido, lo que se pretende con aplicar la inteligencia artificial al Derecho no es que los sistemas expertos sean quienes tomen la decisión, sino brindar ayudas a la rama judicial, especialmente a los jueces, para contar con todos los elementos normativos y jurisprudenciales aplicables en una decisión, agilizando el proceso de investigación que se realiza, así como fundamentando las mismas en cuestiones netamente objetivas.

Por ende, al basar las decisiones judiciales en cuestiones objetivas, sin que tenga influencia excesiva aspectos de la naturaleza humana como estados de ánimo, creencias, entre otros, permite que se pueda garantizar una mayor imparcialidad y exactitud en la decisión misma, lo cual aumenta la confianza que se tiene en los jueces y otorga seguridad jurídica a la ciudadanía en general, incrementándose con ello la favorabilidad que se tiene en la rama judicial.

Por otra parte, se debe resaltar que si bien la aplicación de cualquier herramienta tecnológica, bien sea se trate o no de inteligencia artificial genera unos costos de inversión que suelen ser altos, más aún si se trata de sistemas de expertos; se debe realizar una ponderación analizando todos los beneficios que se traen con su implementación, en donde si bien la principal consecuencia es la agilidad y la consecuente descongestión de la rama, esto a su vez crea confianza en la misma, eliminando al noción de impunidad y otorgando mayor garantía a los derechos de la ciudadanía.

Así, el contar con herramientas basadas en inteligencia artificial ayuda de manera significativa a agilizar los procesos, convirtiéndolos en procesos más rápidos a nivel administrativo 
y judicial, adicionalmente, permite que los fallos se puedan dar de manera más precisa, lo que a su vez genera como ventaja que se disminuyen las probabilidades de error bien sea por no aplicar el precedente judicial o por no dar aplicación a la normativa que corresponde, lo cual da mayor fluidez y confiabilidad a los procesos actuales, beneficiando tanto a las partes de los procesos como a los jueces mismos (LEIVA, CALVO \& ALBAN, 2020).

Finalmente, la responsabilidad por las decisiones que se lleguen a tomar debe recaer en el juez, quien es el que con su propio razonamiento toma la decisión que considere adecuada en el caso concreto, sin que pueda endilgarse la misma a los creadores o diseñadores o a la herramienta misma.

No obstante, pese a que el diseñador no tiene la responsabilidad por la toma de la decisión, sí debe tener responsabilidad al momento de la creación del sistema, previendo los posibles usos que se pueden dar y buscando que la misma esté en sintonía con los principios que tiene una sociedad.

\section{AGRADECIMIENTOS}

Los autores agradecen a la Universidad del Rosario por el financiamiento institucional.

\section{REFERENCIAS}

ALlEN, L. E. (1962). The American Association of American Law Schools Jurimetrics Committee Report on Scientific Investigation of Legal Problems. Saint Louis University Law Journal, v. 7, 39.

AMÉRICA RETAIL. (2019). Opinión: ¿Cómo entender qué es y qué no es Inteligencia Artificial? EMIS University. Recuperado el 19 de febrero de 2020 en: https://www-emis-com.ez.urosario.edu.co/ $\mathrm{php} / \mathrm{search} / \mathrm{doc}$ ?dcid $=647043853 \& \mathrm{ebsco}=1$.

ASENCIO, G. (2018). ¿Podemos confiar en las decisiones sugeridas por algoritmos de inteligencia artificial? Universidad Internacional de Valencia. Recuperado el 26 de marzo de 2020 en: https://www. universidadviu.com/podemos-confiar-en-las-decisiones-sugeridas-por-algoritmos-de-inteligencia-artificial/.

ASOSEC. Asociación colombiana de seguridad. (2018). Inteligencia artificial para el sistema judicial colombiano. Recuperado el 30 de octubre de 2020 en: https: / / asosec.co/inteligencia-artificial-parael-sistema-judicial-colombiano/. 
BADARÓ, S.; IBAÑEZ, L. J.; AGÜERO, M. J. (2013). Sistemas expertos: fundamentos, metodologías y aplicaciones. Ciencia y Tecnología, v. 13, p. 349-364.

BATISTA, N.; NAVARRETE, C. et al. (2019). La toma de decisiones en la informática jurídica basado en el uso de los sistemas de expertos. Revista Investigación Operacional, v. 40, n. 1.

BOSTROM, N.; YUDKOWSKY, E. (2011). The Ethics of Artificial Intelligence. Cambridge Handbook of Artificial Intelligence. William Ramsey and Keith Frankish (Cambridge University Press). Recuperado el 04 de septiembre de 2020 en: https://www.nickbostrom.com/ethics/artificial-intelligence.pdf.

BOTTI, V. (2019). Una inteligencia artificial responsable. El País. Recuperado el 06 de abril de 2020 en: https: / / elpais.com/elpais/2019/07/31/ciencia/1564584742_962030.html.

CABAllerO, L. (2019). Reseña: BARRIO, A. M. (dir.). Derecho de los robots Madrid, La Ley, 2018, 267 p. Revista de Derecho Privado, v. 37, p. 367-371. Recuperado el 06 de abril de 2020 en: https:// dx.doi.org/10.18601/01234366.n37.15.

COECKELBERGH, M. (2019). Artificial Intelligence, Responsibility Attribution, and a Relational Justification of Explainability. Science and Engineering Ethics. Recuperado el 07 de abril de 20202 en: https://doi.org/10.1007/s11948-019-00146-8.

CONSEJO SUPERIOR DE LA JUDICATURA. (2013). Elementos de una metodología para la producción armónica y coherente de la jurisprudencia en Colombia. Bogotá, D.C.

CORPORACIÓN EXCELENCIA EN LA JUSTICIA. (2020). Inventario activo, ingreso y egreso de procesos del Sector Jurisdiccional en Colombia. Recuperado el 31 de marzo de 2020 en: https:// cej.org.co/indicadores-de-justicia/efectividad/inventario-activo-ingreso-y-egreso-de-procesos-delsector-jurisdiccional-en-colombia/.

CORTE CONSTITUCIONAL. Sentencia C-242 de 1997. MP: Dr. Hernando Herrera Vergara. 20 de mayo de 1997.

CORTE CONSTITUCIONAL. Sentencia C-836 de 2001. MP: Dr. Rodrigo Escobar Gil. 09 de agosto de 2001.

CORTE COnstitucional. Sentencia C-284 de 2015. MP: Dr. Mauricio González Cuervo. 13 de mayo de 2015. 
CORVALÁN, J. G. (2017). La primera inteligencia artificial predictiva al servicio de la Justicia: Prometea. La ley. Recuperado el 20 de febrero de 2020 en: https://ialab.com.ar/wp-content/uploads/2019/ 05/Art\%C3\%ADculo-Juan-La-Ley.pdf.

CORVALÁN, J. G. (2018). Inteligencia artificial: retos, desafíos y oportunidades-Prometea: la primera inteligencia artificial de Latinoamerica al servicio de la justicia. Revista de Investigações Constitucionais, v. 5, n. 1, p. 295-316.

DE TRAZEGNIES, F. (2013). ¿Seguirán existiendo jueces en el futuro?: el razonamiento judicial y la inteligencia artificial. Ius et Veritas, v. 23, n. 47, p. 112-130.

EL ESPECTADOR. (2018). Estudio advierte que tres de cada diez colombianos se toman la justicia por cuenta propia. Recuperado el 30 de octubre de 2020 en: https: / www.elespectador.com/noticias / judicial/estudio-advierte-que-tres-de-cada-diez-colombianos-se-toman-la-justicia-por-cuenta-propia/.

ESTEVADEORDAl, A.; BEliZ, G.; ESTEVEZ, E.; OVANESSOFF, A.; PLASTINO, E.; RAO, A.; GILLIAM, M. (2018). Algoritmolandia: inteligencia artificial para una integración predictiva e inclusiva de América Latina. Revista Integración y Comercio, BID, n. 22.

GARCÍA, J. H. (2018). El papel del abogado frente a la inteligencia artificial. Informática y Derecho. Revista Iberoamericana de Derecho Informático. Segunda época, v. 5.

GESTIÓN. (2019). Estonia piensa en una IA que podría ser juez. Recuperado el 04 de septiembre de 2020 en: https://gestion.pe/tecnologia/ estonia-piensa-ia-juez-262912-noticia/?ref=gesr.

GONZÁLEZ, M.; MARTÍNEZ, D. (2020). Dilemas éticos en el escenario de la inteligencia artificial. Economía y Sociedad, v. 25. n. 57, p. 1-17.

JYOTI, R. (2019). Why organizations want consumption-based artificial intelligence pricing. IDC. Anlyse the Future. Recuperado el de septiembre de 2020 en: https://blogs.idc.com/2019/09/11/ why-organizations-want-consumption-based-artificial-intelligence-pricing/.

LEIVA, L. A.; CALVO, B.; ALBAN, F. (2020). Inteligencia artificial para la transformación digital en toma de decisiones. Tecnología Vital, v. 17.

LINARES, F. M. (2018). Inteligencia artificial y justicia penal: más allá de los resultados lesivos causados por robots. Revista de Derecho Penal y Criminología, v. 20, p. 87-130, en: https://doi.org/ $10.5944 /$ rdpc. 20.2018.26446. 
LONDOÑO, M. (2008). La congestión y la mora judicial: el juez, ¿su único responsable? Revista Facultad de Derecho y Ciencias Políticas, v. 38, n. 109, p. 285-419.

LÓPEZ, B. (2017). Introducción a la Inteligencia Artificial. Instituto Tecnológico de Nuevo Laredo. México. Recuperado el 19 de febrero de 2020 en: http: / / itnuevolaredo.edu.mx/takeyas/Articulos/Inteligencia\% 20Artificial/ARTICULO\%20Introduccion\%20a\%20la\%20Inteligencia\%20Artificial.pdf.

LÓPEZ DE MÁNTARAS, R. (2015). Algunas reflexiones sobre el presente y futuro de la Inteligencia Artificial. Novática, v. 234, n. 4, p. 97-101. Recuperado el 07 de abril de 2020 en: http: / /hdl.handle.net/ $10261 / 136978$.

MAN QI; WENZHANG TANG. (2018, julio). Analysis on Artificial Intelligence Security and Its Countermeasures. $3^{\text {rd }}$ International Conference on Contemporary Education, Social Sciences and Humanities (ICCESSH 2018). Recuperado el 07 de abril de 2020 en: https: / / doi.org/10.2991/iccessh-18.2018.242.

MARÍN, S. (2019). Ética e inteligencia artificial. Cuadernos de la Cátedra CaixaBank de Responsabilidad Social Corporativa, n. 42. Recuperado el 07 de abril de 2020 en: https://dx.doi.org/10.15581/018.ST-522.

MARTÍNEZ, G. C. (2018). La inteligencia artificial y su aplicación al campo del Derecho. Alegatos-Revista Jurídica de la Universidad Autónoma Metropolitana, v. 26, n. 82, p. 827-846.

MINISTERIO DE HACIENDA Y CRÉDITO PÚBLICO. (2019). Decreto 2411 de 2019. Por el cual se liquida el Presupuesto General de la Nación para la vigencia fiscal de 2020, se detallan las apropiaciones y se clasifican y definen los gastos.

MiTTELSTADT, B. D.; AllO, P.; TADDEO, M.; WATCHER, S.; FLORIDI, L. (2016). The ethics of algorithms: Mapping the debate. Big Data \& Society, v. 3, n. 2. Recuperado el 03 de septiembre de 2020 en: https: / / doi.org/10.1177/2053951716679679.

MONTREAL DECLARATION FOR A RESPONSIBLE DEVELOPMENT OF ARTIFICIAL INTELLIGENCE. (2018). [Pronunciada en la clausura del Forum on the Socially Responsible Development of AI.]

NARVÁEZ, C. (2018). Inteligencia artificial para el sistema judicial colombiano. Ámbito Jurídico. Recuperado el 03 de abril de 2020 en: https://www.ambitojuridico.com/noticias/tecnologia/tic/ inteligencia-artificial-para-el-sistema-judicial-colombiano-opinion.

NAVA, W. (2019). Inteligencia artificial para la solución de Controversias del Acuerdo Comercial de América del Norte. Revista Jurídica IURA, v. 4, n. 1. 
NEWSWIRES, B. M. (2020). Artificial intelligence and ethical responsibility. Minnesota Lawyer. Recuperado el 22 de abril de 2020 en: https: / / minnlawyer.com/2020/03/30/artificial-intelligenceand-ethical-responsibility/.

OVANESSOFF, A.; PLATINO, E. (2017). Cómo la inteligencia artificial puede generar crecimiento en Sudamérica. Informe Accenture. Recuperado el 01 de septiembre de 2020 en: https: / www.accenture. com/_acnmedia/PDF-49/Accenture-Como-la-IA-Puede-Generar-Crecimiento-En-Sudamerica. $\operatorname{pdf} \#$ zoom $=50$.

PASCUAL, D. A. (2017). Inteligencia artificial: un panorama de algunos de sus desafíos éticos y jurídicos. Universidad de Girona. Recuperado el 04 de septiembre de 2020 en: https://dugi-doc. udg.edu/bitstream/handle/10256/14950/alvaro-pascual.pdf?sequence $=1$.

PONS, M. (2018). Inteligencia artificial y proceso judicial. Jordi Nieva Fenoll.

RAMÍREZ,Y. (2006). Seguridad jurídica. Corte Suprema de Justicia. Revista número 21. Bogotá D.C.

REYES, P. (2019). Servicios Legaltech. Revista Iberoamericana de Derecho Informático (Segunda época). Federación Iberoamericana de Asociaciones de Derecho e Informática.

RIBAS, M. (2019). Inteligencia artificial, sinónimo de crecimiento. Dinero. Recuperado el 01 de septiembre de 2020 en: https: / /www.dinero.com/tecnologia/articulo/inteligencia-artificial-sinonimo-de-crecimientopor-marco-ribas/270042.

RODRÍGUEZ, I. (2019). De la inteligencia artificial a la moral artificial. Posibilidades y consideraciones éticas. Universitat Jaume.

ROMINA, G. (s.f.). La inteligencia artificial y el acceso a la tutela judicial efectiva de las personas en Estado de vulnerabilidad.

SAMACÁ, A. F. (2016). Inteligencia artificial aplicada al Derecho. Bogotá, D. C., Universidad Santo Tomás.

SIERRA, G. (2019). Entrevista realizada en informe: Prometea, inteligencia artificial para la revisión de tutelas en la Corte Constitucional. Legis. Ámbito Jurídico.

SUSSKIND, R.; SUSSKIND, D. (2016). El futuro de las profesiones. Cómo la tecnología transformará el trabajo de los expertos humanos. Teell Rd., Traducción Ruiz Franco, JC Zaragoza, p. 65-69.

TADDEO, M.; FLORIDI, L. (2018). How AI can be a force for good. Science, v. 361, n. 6404, p. 751-752. 
THETECHNOLAWGIST. (2019). Estonia se prepara para tener “jueces robot” basados en inteligencia artificial. Recuperado el 04 de septiembre de 2020 en: https://www.thetechnolawgist.com/2019/ 06/12/ estonia-se-prepara-para-tener-jueces-robot-basados-en-inteligencia-artificial/7.

TIQUE, L. A. (2018). La responsabilidad del Estado colombiano como consecuencia del fenómeno de la mora judicial.

TRT. (2020). Tribunal de Internet de Beijing lanza juez de inteligencia artificial “AI Judge”. Recuperado el 04 de septiembre de 2020 en: https://www.trt.net.tr/espanol/ciencia-y-tecnologia/2019/06/28/ tribunal-de-internet-de-beijing-lanza-juez-de-inteligencia-artificial-ai-judge-1226593.

UNIVERSITÉ DE MONTRÉAL. (s.f.). The Montreal Declaration for the Responsible Development of Artificial Intelligence was launched today, outlining principles and making recommendations. Udemnouvelles. Recuperado el 30 de octubre de 2020 en: https://nouvelles.umontreal.ca/en/article/2018/12/04/ developing-ai-in-a-responsible-way/.

WEI, J. (2019). Inteligencia artificial en China. ADefinitas. Recuperado el 04 de septiembre de 2020 en: https://adefinitivas.com/arbol-del-derecho/nuevas-tecnologias/inteligencia-artificial-en-china/.

\section{COMO CITAR ESTE ARTIGO:}

CÁRDENAS, Erick Rincón; MOLANO, Valeria Martinez. Un estudio sobre la posibilidad de aplicar la inteligencia artificial en las decisiones judiciales. Revista Direito GV, v. 17, n. 1, jan./abr. 2021, e2101. doi: http://dx.doi.org/ 10.1590/2317-6172202101.
Erick Rincón Cárdenas

Abogado de la Universidad del Rosario, Bogotá, Colombia. Doctor en Derecho de la Universidad Europea de Madrid. erick.rinconaurosario.edu.co

\section{Valeria Martinez Molano}

Abogada de la Universidad del Rosario, Bogotá, Colombia. Cursa maEstría en DERECho EN la misma universidad. valeria.martinezQurosario.edu.co 